\title{
A nova Política Nacional de Atenção Básica à Saúde: impactos perceptíveis em uma equipe de saúde da família no município de Alagoa Nova-PB
}

\author{
Kleiton Wagner Alves da Silva Nogueira ${ }^{1}$ \\ Severino Justino Sobrinho ${ }^{2}$
}

Resumo: $\mathrm{O}$ presente artigo tem por objetivo analisar o debate nacional a respeito das alterações da Política Nacional de Atenção Básica à Saúde (PNAB), bem como verificar o conhecimento dessas mudanças em uma Equipe de Saúde da Família, especificamente no município de Alagoa Nova-PB. Ao utilizar como aporte metodológico o levantamento bibliográfico em periódicos acadêmicos e livros que versam sobre o tema, junto à realização de entrevistas, foi possível constatar que em meio a um processo de conturbação política com o impeachment da presidente Dilma Roussef, a alteração da PNAB não contou com ampla participação dos trabalhadores da atenção básica, em especial, dos agentes comunitários de saúde, caracterizando a burocratização e verticalização das decisões em âmbito nacional. Esse processo também foi corroborado no plano local, tendo em vista o nível de desarticulação e desconhecimento das alterações da PNAB, com o papel destacado pela ausência de diálogo entre Conselho Municipal de Saúde e Estratégia de Saúde da Família no município analisado. Para além do campo institucional, foi possível perceber que devido ao recente quadro de crise econômica e política, a Atenção Básica à saúde passa a ser alvo de uma flexibilidade ancorada na austeridade fiscal em âmbitos nacional e local.

Palavras-chave: Atenção básica à saúde. Estratégia Saúde da Família. Sistema Único de Saúde.

\begin{abstract}
This paper analyze the national debate about changes in the National Policy of Primary Health Care (PNAB), as well as to verify the knowledge of these changes in a family health team in the municipality of Alagoa Nova-PB. Using as methodological contribution the bibliographic survey in academic journals and books that deal with the theme, along with interviews, it was possible to verify that in the midst of a process of political turmoil with the impeachment of President Dilma Roussef, the process of alteration of the PNAB It did not count on the broad participation of primary care workers, especially the Community Health Agents, characterizing the bureaucratization and verticalization of decisions at the national level. This process was also corroborated at the local level, given the level of disarticulation and lack of knowledge of PNAB changes, with the role highlighted by the absence of dialogue between the Municipal Health Council and the Family Health Strategy in the municipality analyzed. In addition to the institutional field, it was also possible to realize that due to the recent economic and political crisis, Primary Health Care becomes the target of a flexibility anchored in fiscal austerity at the national and local levels.
\end{abstract}

Keywords: Basic health care. Family health strategy. Health Unic System.

\footnotetext{
${ }^{1}$ Graduado em Geografia pela Universidade Federal de Campina Grande (UFCG); Graduado em Administração pela Universidade Estadual da Paraíba (UEPB); Mestrando pelo Programa de Pós-Graduação Em Ciências Sociais da UFCG, Brasil. Integrante do Grupo de Estudos e Pesquisas sobre Estado e Luta de Classes na América Latina (PRÁXIS). E-mail: kleiton_wagner@hotmail.com.

${ }^{2}$ Graduado em Geografia pela Universidade Federal de Campina Grande (UFCG). Especialista em Análise Regional e Ensino de Geografia (UFCG). Mestre em Desenvolvimento Regional (PGGDR) pela Universidade Estadual da Paraíba (UEPB). E-mail: severinojustinogeografo@gmail.com.
} 


\section{Introdução}

A Atenção Básica (AB) à saúde implica no cuidado sistematizado e estratégico dos problemas de saúde da população. No Brasil, essa instância tem como estruturação a Política Nacional de Atenção Básica (PNAB) que desde 2006 incorpora mecanismos e formas de organização dessa modalidade de atenção no território nacional. Considera-se que a PNAB possui na Saúde da Família sua principal estratégia de atuação, porquanto trabalha com a concepção de equipes de saúde multiprofissional, contendo: Médico, Enfermeiro, Dentistas e os Agentes Comunitários de Saúde (ACS). Essa política é importante por apresentar sucesso na melhoria das condições de saúde da população, explicados pela expansão de atendimentos à comunidade via aumentos de unidades de saúde e de equipes de Saúde da Família (eSF) (MARTINS, 2017).

Mesmo com bom desempenho, a PNAB é alvo de transformações que implicam em sua forma de organização e sistematização (BRASIL, 2011; 2012; 2017). A mais recente dessas reformulações diz respeito à Portaria n 2.436, de 21 de setembro de 2017, que provocou uma série de dúvidas e debates sobre a organização das ações e serviços de saúde (RADIS, 2017). Desse modo, reflete-se sobre o fato dessa reformulação ser projetada em um cenário desfavorável para a manutenção das políticas públicas no Brasil, devido a crise econômica e política que o país vivencia (MOROSINI; FONSECA, 2017; BATALHA; LAVOR, 2017; MATHIAS, 2017). Além desse elemento, Martins (2017); Morosini e Fonseca (2017) apontam que a pactuação das mudanças foi realizada de forma bastante conturbada e sem amplo debate democrático, o que implicou em uma PNAB flexível ao enquadramento de um cenário de austeridade fiscal.

Nesse contexto, devido à importância em entender a recente mudança dessa política, e a dificuldade de encontrar trabalhos que abordem sobre esse fato, buscou-se analisar o processo de debate nacional a respeito das alterações da PNAB, assim como verificar o conhecimento dessas mudanças em uma eSF do município de Alagoa Nova, no Estado da Paraíba, fazendo assim, uma reflexão em torno do cenário nacional ao local. De tal modo, por meio do levantamento bibliográfico e entrevistas, a pesquisa vislumbra a inter-relação entre um processo macro institucional oriundo do campo político e sua materialização e aceitação em um plano local. Nesse sentido, frente ao Impeachment da presidente Dilma Roussef em 2016, faz-se importante visualizar como todo este cenário tem se manifestado no setor da saúde, em especial no que diz respeito à PNAB. Entende-se que pelo fato de ser um fenômeno recente, a busca por informações, discussões, pontos de defesa e de discordância são elementos importantes para que se possa entender de forma mais global como essas mudanças afetam esta política e consequentemente à sociedade.

\section{Metodologia}

A pesquisa foi realizada em dois momentos, um primeiro associado ao âmbito nacional, mediante levantamento bibliográfico em periódicos acadêmicos e livros acerca do tema, e, em um segundo 
momento, por meio do trabalho de campo realizado em uma eSF do município de Alagoa Nova, Estado da Paraíba, município possui uma população estimada de 20.689 habitantes para o ano de 2017 (IBGE, 2017). A Unidade sede da equipe estudada fica localizada na zona rural e comporta três ACS, e, na unidade Âncora, localizada na zona urbana, há dois ACS. Conforme dados da Secretaria Municipal de Saúde, a Unidade estudada possui a menor densidade populacional entre as oito existentes no Município. Contudo, sua área geográfica engloba quase um terço do território municipal.

Como caracterização do estudo, a pesquisa é classificada como exploratória e descritiva, por considerar que essa subsidia o pesquisador na busca por registros de fatos acerca da realidade, proporcionando proximidade com o tema estudado (GIL, 2002; 2008; BONI; QUARESMA, 2005; SEVERINO, 2007; PRODANOV, 2013). No que diz a respeito à análise do problema abordado, foram utilizadas as seguintes técnicas de coleta de informações: a) levantamento bibliográfico; b) entrevistas semiestruturadas junto à equipe estudada e c) anotações em diário de campo. A escolha pela técnica da entrevista semiestruturada deu-se pelo fato desta proporcionar uma visão mais aprofundada do problema abordado, por intermédio da combinação de perguntas abertas e fechadas, o que ajudou na delimitação do tema tratado (BONI; QUARESMA, 2005). Desse modo, foram realizadas oito entrevistas com os profissionais dessa equipe.

Nesse ínterim, se destaca o cuidado de não citar o nome da eSF e da sua localização como forma de garantir o sigilo dos profissionais entrevistados. Salienta-se que nos resultados do estudo ao se mostrar os diálogos e discursos, foram utilizados nomes fictícios, escolhidos pelos profissionais no momento da entrevista. O diário de campo foi importante por proporcionar a inserção de conteúdos observados no momento da realização da entrevista, como um meio de captar a memória de curto prazo do pesquisador. Dessa forma, foram anotados impressões e percursos do trabalho de campo para o subsídio da análise das informações.

Após a coleta de informações, utilizou-se da análise de conteúdo como forma de sistematização e apreciação do material coletado. Com base nas observações de Laville e Dione (1999), optou-se pelo uso do modelo misto de categorias analíticas, uma vez que este proporciona a seleção de categorias iniciais, mas com possibilidade de modificação durante a própria análise do conteúdo.

\section{Resultados e discussão}

A atenção básica $(\mathrm{AB})$ à saúde é caracterizada por ações que variam da esfera individual à coletiva, e abrange a promoção, a proteção, a prevenção de agravos, o diagnóstico, o tratamento, a reabilitação e a manutenção da saúde. Considera-se que a $\mathrm{AB}$ é a principal via de acesso ao SUS, devendo ser ofertada de forma integral e gratuita, com base nas necessidades e demandas do território (BRASIL, 2012). De forma institucionalizada, esta instância do SUS foi estabelecida pela portaria $n^{\circ}$ 648, de 28 de março de 2006, que 
aprovou a Política Nacional de Atenção Básica. Contudo, com o passar do tempo e das diferentes gestões, essa política sofreu alterações, sendo a mais recente delas, a Portaria no 2.436, de 21 de setembro de 2017.

É possível observar no quadro 1 a síntese com as mudanças na PNAB com o passar dos anos.Todavia, dentro de um recente âmbito permeado por crise econômica, política e pela austeridade fiscal, a reformulação da PNAB surtiu debates e críticas de algumas instâncias organizadas da sociedade. Para Morosini e Fonseca (2017) , a revisão dessas diretrizes foi realizada em um período delicado visto as restrições impostas aos gastos do Estado perante as políticas públicas, tendo como representante normativo maior a Emenda Constitucional número n 95/2016. Além desse elemento, reflete-se também que o processo da própria aprovação e discussão não teve o pleno crivo da sociedade e dos grupos de profissionais como lidam diretamente com o tema. Segundo afirmam Batalha e Lavor (2017), com base em entrevista de Liu Leal, representante do Centro Brasileiro de Estudos de Saúde (Cebes) no Conselho Nacional de Saúde (CNS), as decisões políticas foram tomadas de forma autoritária e antidemocrática, principalmente no caso dessas reformulações em torno da PNAB.

Quadro 01: Evolução normativa da Política Nacional de Atenção Básica

\begin{tabular}{|c|l|}
\hline Legislação & \multicolumn{1}{|c|}{ Mudanças } \\
\hline $\begin{array}{c}\text { Portaria } \mathrm{n}^{\circ} \text { 648/GM } \\
\text { de } 28 \text { de março de }\end{array}$ & $\begin{array}{l}\text { Revisão de diretrizes e normas para o Programa Saúde na Família (PSF) e } \\
\text { também para o Programa Agentes Comunitários de Saúde (PACS). A PNAB } \\
\text { definiu como imprescindível a constituição de equipe multiprofissional } \\
\text { composta por médico, enfermeiro, cirurgião dentista, auxiliar de consultório } \\
\text { dentário ou técnico em higiene dental, auxiliar de enfermagem ou técnico de } \\
\text { enfermagem e agente comunitário de saúde, entre outros. Todos esses } \\
\text { trabalhadores tinham a obrigação de cumprir jornada de trabalho de 40 horas } \\
\text { semanais. Para a implantação das Equipes de Saúde da Família, a política } \\
\text { determinava inicialmente que cada equipe multiprofissional ficaria responsável } \\
\text { pelo atendimento de, no máximo, quatro mil habitantes, sendo a média } \\
\text { recomendada de três mil. A equipe prevista contava com até doze Agentes } \\
\text { Comunitários de Saúde (ACS), sendo que cada um deles tinha o dever de } \\
\text { acompanhar, no máximo, 750 pessoas. }\end{array}$ \\
\hline $\begin{array}{c}\text { Portaria no 2.488, de } \\
21 \text { de outubro de } \\
2011 .\end{array}$ & $\begin{array}{l}\text { Mudou o parâmetro de 30 mil habitantes para cada unidade, definido na versão } \\
\text { anterior, para 18 mil habitantes, em casos de unidades sem Saúde da Família } \\
\text { em grandes centros urbanos. Já em casos de UBS com Saúde da Família, } \\
\text { manteve o número de 12 mil pessoas por unidade. Houve mudanças no } \\
\text { sentido de reconhecer a modelagem das equipes de atenção básica, ficou } \\
\text { permitida a formação de equipes com um ou mais médicos, cada um deles com } \\
\text { carga horária semanal de 20, 30 ou 40 horas. A política definida em 2011 } \\
\text { ampliou o número de municípios que poderiam ter os Núcleos de Apoio à } \\
\text { Saúde da Família (NASF). Também regulamentou os Consultórios de Rua e } \\
\text { simplificou as condições para que fossem criadas UBS Fluviais e ESF para as } \\
\text { Populações Ribeirinhas, ações importantes para atender populações inseridas }\end{array}$ \\
\hline
\end{tabular}




\begin{tabular}{|c|l|}
\hline & em contextos específicos. \\
\hline $\begin{array}{c}\text { Portaria no 2.436, de } \\
21 \text { de setembro de } \\
2017 .\end{array}$ & $\begin{array}{l}\text { Incorpora o debate da integração da Atenção Básica com a Vigilância em } \\
\text { Saúde, especialmente por meio do trabalho articulado entre ACS e ACE. Traz } \\
\text { mudanças referentes a equipes de AB e a carga-horária dos profissionais. } \\
\text { Institui a realização de procedimentos técnicos pelos ACS. }\end{array}$ \\
\hline
\end{tabular}

Fonte: Elaborado com base em Brasil (2012) e Martins (2017).

Outro traço contraditório que merece menção é que no processo de revisão desta política o CNS não foi plenamente consultado, como atesta a conselheira nacional de saúde Shirley Díaz Morales, em reportagem à Radis comunicação em Saúde.

O papel do Conselho Nacional de Saúde não é apenas de instância consultiva, mas de instância deliberativa em relação às políticas públicas de saúde. E infelizmente isso não está sendo respeitado. A revisão da Pnab, ainda em 2016, começou a ser tratada apenas na CIT [Comissão Intergestores Tripartite]. O CNS tomou ciência da situação e levou ao pleno que havia essa discussão entre gestores, sem a participação de usuários e trabalhadores (BRASIL, 2017, p. 32).

Ainda de acordo com a aludida conselheira, o CNS procurou ter acesso ao conteúdo do texto e discussão que ocorria dentro da CIT, para que os trabalhadores e usuários do SUS pudessem se debruçar e fazer suas contribuições, não obstante, sem grande sucesso quanto ao acesso a esse material. Para Mathias (2017), a pactuação em torno da nova PNAB foi realizada de forma rápida pela CIT. Além disso, a formação de um consenso em prol das mudanças já tinha se formulado há um tempo, o que permitiu uma aprovação quase que de forma instantânea. Observa-se a este modo, que a participação teve seletividade e a discussão foi restrita. Este elemento parece endossar o momento atual pelo qual o Brasil vivencia. Para isto, basta que se reflita sobre alterações em um curto espaço de tempo sobre temas referentes à legislação trabalhista, previdenciária e de regime fiscal, as quais refletem um ataque frontal do neoliberalismo, utilizando-se das contrarreformas nas políticas sociais.

Embora esse cenário macroinstitucional seja o oposto da proposta democrática do SUS, percebemos também que numa escala local própria, as noções de participação e de deliberação se coadunam como processo de burocratização. No tópico a seguir podemos observar, de forma mais nítida, a opinião dos profissionais de saúde consultados a respeito desse panorama de mudanças que elencamos. 


\section{Discurso local sobre mudanças da nova PNAB}

As informações trabalhadas a seguir são oriundas do trabalho de campo realizado em uma Unidade Básica de Saúde da Família do município de Alagoa Nova, Paraíba. Como expresso na metodologia, procurou-se realizar entrevistas com os profissionais dessa equipe, como uma forma de visualizar o processo de entendimento e discussão das formulações da política em âmbito local.

\section{Perfil da equipe entrevistada}

A equipe analisada possui oito profissionais divididos entre as seguintes categorias: médico, enfermeiro, técnico em enfermagem e cinco Agentes Comunitários de Saúde. A média de idade dos profissionais fica em torno de trinta e nove anos. O profissional mais novo possui cerca de dezenove anos de idade; já o profissional com idade mais avançada no grupo possui cerca de quarenta e seis anos.

Desses profissionais, um possui ensino médio incompleto, quatro ensino médio completo e três ensino superior. O tempo de trabalho desses profissionais na $\mathrm{AB}$ varia bastante, sendo seis meses o tempo de trabalho da profissional com vínculo mais recente e cerca de vinte e sete anos o mais experiente. Cabe destacar que o profissional com vinte e sete anos de experiência de trabalho foi um dos pioneiros a trabalhar com Atenção Básica à Saúde, e isso no início da implantação do Programa dos Agentes Comunitários de Saúde (PACS) no município de Alagoa Nova.

No que diz respeito ao vínculo empregatício desses profissionais, cinco deles estão inseridos no regime estatutário e os três restantes tiveram acesso à função por meio do contrato de trabalho fixado com a prefeitura municipal. Sobre a renda desses profissionais, tem-se que a menor remuneração é de mil e quatorze reais, e a mais alta fica em torno dos seis mil reais. Nesse ponto chamamos atenção para a disparidade de salários dentro de uma mesma equipe, fato que repercute também na forma como esses profissionais se sentem valorizados. É comum que categorias como a dos médicos e dos enfermeiros ganhem salários mais altos nas unidades, materializando, assim, uma clara subdivisão no patamar salarial desses profissionais. Desde já, salientamos que os trabalhos dos ACS são tão importantes quanto a do médico e do enfermeiro, tendo em vista que na maioria das vezes é o ACS que realiza o processo de trabalho de campo e acompanhamento das famílias.

\section{Dinâmica e condições de trabalho}

De acordo com a realização das entrevistas foi possível observar que os profissionais cumprem a carga horária de quarenta horas semanais estipulada em lei. No caso dos ACS há uma maleabilidade na 
forma como esse horário é cumprido, tendo em vista que desde que o profissional alcance à meta estipulada para o mês, há a possibilidade de realizar outras atividades que, em princípio, demandem menos tempo ou que não exijam o trabalho em campo. Essa questão da maleabilidade também é reforçada pela ACS Kiara; segundo essa profissional, o seu trabalho possibilita a própria organização do horário, desde que às oito horas sejam efetivadas. Nesse sentido, vejamos excerto da sua exposição, verbis:

\begin{abstract}
A nossa carga horária é de quarenta horas, mas a gente faz nosso trabalho. A gente faz como se diz assim o nosso horário. Tem dias que eu saio sete horas e chego de duas horas ou três horas da tarde porque eu tiro direto. Porque além de eu ser agente de saúde eu sou mãe, esposa, dona de casa, e eu preciso dividir essas funções durante o dia. (Kiara).
\end{abstract}

Para as outras categorias de profissionais da equipe, a exemplo da categoria dos médicos, dos enfermeiros e dos técnicos em enfermagem, as atividades são realizadas na própria Unidade, além de visitas à comunidade, que contam com pré-agendamento. Além disso, esses profissionais também vão a campo, segundo informações cedidas nas entrevistas.

Outro elemento que chamou atenção na realização das entrevistas remete às dificuldades enfrentadas por esses profissionais no seu cotidiano de trabalho. Dentre os problemas mais citados, a questão da acessibilidade à residência dos usuários cadastrados ganha destaque, devido à atuação ocorrer predominantemente em zona rural, cuja distância entre as residências possuem um raio de deslocamento grande. Outros problemas citados em menor escala seriam: a ausência de insumos para as atividades, a exposição ao sol na realização das visitas em campo, a falta de transporte para locomoção da equipe e a ausência de pessoas nas residências nos dias de visita dos ACS.

\title{
Discursos sobre o acesso e debates a nova PNAB
}

Segundo as informações produzidas por intermédio do trabalho de campo, foi possível constatar que a discussão da nova PNAB foi breve e, na maioria dos casos, se deu por via informal, com o auxílio de conversas e grupos em redes sociais. Para os ACS, além da coordenação da AB no município, outra instituição que ajudou um pouco nesse debate foi a Associação dos Agentes de Saúde de Alagoa Nova. Segundo relato dos entrevistados, as discussões nesses espaços não se aprofundaram muito, o que abriu lacunas no entendimento da legislação. 
Nas instâncias participativas como o Conselho Municipal de Saúde, os profissionais relataram que não tiveram conhecimento reuniões, debates ou eventos que tratassem desse tema. Sem embargo, não se pode afirmar que não houve alguma mobilização por parte desta instituição. De tal modo, a pesquisa adota um recorte analítico que consente que todos os entrevistados não tinham conhecimento sobre o papel do conselho nessa questão. Isso demonstra que o Conselho Municipal de Saúde de Alagoa Nova$\mathrm{PB}$, de acordo com os entrevistados, não possui um papel ativo no que se refere à representatividade e à promoção da saúde para os seus munícipes. Além disso, os profissionais entrevistados relataram que o corpo técnico e a representação social desse conselho são formados para beneficiar interesses políticos locais. Exemplo dessa circunstância, tem-se um dos relatos dos entrevistados:

[...] quando é para beneficiar assim o município, aí é implantado, quando é para agarrar alguma coisa, tem aquela necessidade de implantar aquele conselho aí todo mundo corre atrás, para formalizar aquilo ali, aí quando abraça aquilo ali, um projeto, aí parece que a coisa fica diferente ou então quando muda de gestão. (JESSÉ).

Segundo relato de outro profissional, há dúvidas quanto à real composição do Conselho, dando a entender que há um forte corporativismo relacionado à gestão municipal frente a esse órgão. Vejamos:

Outra questão é observar quem está nesses conselhos, por que é um ambiente importante para ver como é que está a saúde do município, mas quem é que está à frente? Quem foi consultado para participar? Geralmente são pessoas que são colocadas lá, porque são da gestão. (CHICO).

Para Silva, Lima Silva e Souza (2013) com base em estudos realizados sobre os conselhos de Saúde, no Brasil há apontamentos de uma profunda distância entre o espírito da Lei 8.142/90 e a realidade desses colegiados. Ainda segundo esses autores, há indícios de forte centralização da tomada de decisão nos conselhos por parte das gestões municipais.

Outro elemento de destaque refere-se ao período de quinze dias para a realização de consulta pública sobre a reformulação da PNAB. Nesse ponto em especial, nenhum dos entrevistados participou da consulta pública, precisamente por não terem acesso a essa informação em momento oportuno. Somado a esse problema de participação na reformulação dessa política, os pontos negativos mais citados, segundo os sujeitos entrevistados, foram: a diminuição do número de ACS, a perda de vínculo com a comunidade e a não obrigatoriedade do ACS na equipe de Atenção Básica (eAB). De acordo com o entendimento dos entrevistados, o fato de haver a possibilidade de diminuição dos ACS devido à 
formatação das equipes de Atenção Básica, é um ponto negativo. Há o entendimento de que se houver uma diminuição de ACS, consequentemente haverá uma perda do vínculo entre comunidade e Unidade de Saúde. Essa preocupação, para uma parte da equipe entrevistada, é reforçada quando se tem na nova PNAB a possibilidade de realização de procedimentos técnicos, tais como: verificação de pressão arterial, glicemia etc. Para alguns profissionais da equipe, esse fato pode caracterizar sobrecarga ao ACS, assim como tornar a $\mathrm{AB}$ um serviço de demanda e não de promoção à saúde.

Além dessas preocupações referentes à formatação das equipes de Atenção Básica e a realização de procedimentos técnicos, a restrição orçamentária também foi citada. $\mathrm{Na}$ fala dos profissionais eles identificam contradição por parte do governo, tendo em vista que este pretende melhorar a qualidade da $A B$, porém impõe restrição orçamentária. Diante disso, Radis (2017) expressa que um dos primeiros impactos dessas medidas que, em grande maioria, foram também percebidas pelos entrevistados desse estudo, é que a ESF dentro da AB como rede ordenadora, deixa de ser prioridade e passa a ser uma opção, tendo em vista que o gestor terá maior flexibilidade em formar eAB sem a presença do ACS.

Segundo uma das profissionais entrevistadas, essa 'tática' parece seguir o viés econômico, uma vez que uma equipe de Atenção Básica poderá custar menos do que uma equipe de Saúde da Família. Nesse sentido, in verbis:

Eu acho porque se para a gestão for mais viável né, eles vão querer o que é mais viável para eles. Isso aí a gente sabe, porque a gente sabe que uma equipe da Atenção Básica deve sair bem menos custoso do que a equipe de Saúde da Família, então eu acho que se for mais viável para eles, vai acabar que eles podem querer de deixar só equipes de Atenção Básica porque já que o custo é menor e for mais viável. (MARIA).

Dentro desse debate, Campos (2016) aponta que é justamente a questão do subfinanciamento da política pública de saúde que caracteriza um dos maiores problemas do SUS, uma vez que se trata já de um consenso, especificamente no movimento sanitário, que faltam recursos para o investimento na saúde pública. Ademais, a Emenda Constitucional no 95/2016 e seu caráter restritivo de investimentos públicos, é um forte indício de um movimento dentro do campo político nacional para a redução do tamanho Estado em termos de investimento nas políticas públicas. Essa constatação influencia na forma como as políticas sociais e, em especial, a saúde será financiada. Por se tratar de um mecanismo de contenção de gastos, essa emenda influenciará de forma direta na PNAB (EPSJV, s.d).

\section{Pontos de inflexão da nova PNAB}

Entre as mudanças trazidas pela reformulação da PNAB que chamou atenção por parte dos profissionais entrevistados, destacam-se: a composição da equipe de Atenção Básica, a carga-horária dos profissionais nessa equipe, e as novas funções que podem ser acrescidas ao trabalho do ACS. Para a 
legislação referente à nova PNAB existe diferenças na composição das equipes de eSF e eAB, conforme pode-se observar no quadro 2.

Quadro 02: Diferenças entre eAB e eSF

\begin{tabular}{|c|c|c|}
\hline Modalidade & Conceito & Formação \\
\hline $\begin{array}{c}\text { Equipe de } \\
\text { atenção } \\
\text { básica (eAB) }\end{array}$ & $\begin{array}{l}\text { Esta modalidade deve atender aos } \\
\text { princípios e diretrizes propostas para a } \\
\text { AB. A gestão municipal poderá } \\
\text { compor eAB de acordo com } \\
\text { características e necessidades do } \\
\text { município. }\end{array}$ & $\begin{array}{l}\text { Médicos de preferência com especialidade em } \\
\text { medicina da família e comunidade, enfermeiro } \\
\text { preferencialmente especialista em saúde da } \\
\text { família, auxiliares de enfermagem e ou } \\
\text { técnicos de enfermagem. Poderão agregar } \\
\text { outros profissionais como dentistas, auxiliares } \\
\text { de saúde bucal ou técnicos de saúde bucal, } \\
\text { agentes comunitários de saúde e agentes de } \\
\text { combate a endemias. }\end{array}$ \\
\hline $\begin{array}{c}\text { Equipe de } \\
\text { saúde da } \\
\text { família (eSF) }\end{array}$ & $\begin{array}{l}\text { É a estratégia prioritária de atenção à } \\
\text { saúde e visa à reorganização da AB no } \\
\text { país, de acordo com os preceitos do } \\
\text { SUS. É considerada como estratégia de } \\
\text { expansão, qualificação e consolidação } \\
\text { da AB, por favorecer uma reorientação } \\
\text { do processo de trabalho com maior } \\
\text { potencial de ampliar a resolutividade e } \\
\text { impactar na situação de saúde das } \\
\text { pessoas e coletividades, além de } \\
\text { propiciar uma importante relação } \\
\text { custo-efetividade. }\end{array}$ & $\begin{array}{l}\text { Médico preferencialmente da medicina da } \\
\text { família e comunidade, enfermeiro, } \\
\text { preferencialmente especialista em saúde da } \\
\text { família; auxiliar e/ou técnico de enfermagem e } \\
\text { agente comunitário de saúde, podendo fazer } \\
\text { parte da equipe o Agente de Combate a } \\
\text { Endemias e os profissionais de saúde bucal: } \\
\text { cirurgião-dentista, preferencialmente } \\
\text { especialista em saúde da família, e auxiliar ou } \\
\text { técnico em saúde bucal, de acordo com } \\
\text { definição local. }\end{array}$ \\
\hline
\end{tabular}

Fonte: Elaboração própria, com base em Brasil (2017).

Entretanto, apesar da aparência de ganho de flexibilidade devido a uma possível diminuição de custos na formação de um serviço de atenção básica, a nova PNAB influencia os gestores a um reprocesso de redução do número de agentes comunitários de saúde por equipe de Atenção Básica, implicando, assim, na perda de vínculo entre comunidade e profissionais de saúde. A não inserção obrigatória do agente nessas equipes é um traço marcante dos atuais movimentos da política de austeridade fiscal do governo. Na busca de um "reequilíbrio" do orçamento público, o receituário de diminuição do Estado parece ser a tônica das gestões públicas (MOROSINI; FONSECA, 2017; BATALHA; LAVOR, 2017). Para o grupo entrevistado a não presença do agente comunitário de saúde em uma equipe de Atenção Básica, é algo que poderá vir a ser prejudicial para a atenção básica como um todo, uma vez que este profissional é essencial no elo de uma comunidade com a Unidade de Saúde. 
Morosini e Fonseca (2017) ressaltam que a nova PNAB traduz o momento atual de flexibilização das políticas públicas brasileiras. Mesmo considerando as equipes de saúde da família como prioritárias, o gestor público tem a opção da institucionalização de equipe de Atenção Básica. Para as autoras fica nítido que haverá uma maior preponderância da perspectiva biomédica e desvirtuamento das ideias de promoção à saúde. Desconsiderar a relevância do agente comunitário de saúde revela a dificuldade de superação do modelo clínico e a não ênfase da saúde em seu modo integral.

Outro fato que merece destaque diz respeito à diferença de carga-horária dessas unidades de saúde. Para uma equipe de saúde da familia existe a obrigatoriedade de cumprimento de 40 horas semanais de trabalho para todos os profissionais, sendo que esses poderão estar vinculados a apenas uma equipe. Por outro lado, na equipe de atenção básica existe uma flexibilidade na questão da carga-horária. Para essa modalidade de equipe, o cumprimento da carga horária funcionará da seguinte forma:

A composição da carga horária mínima por categoria profissional deverá ser de 10 (dez) horas, com no máximo de 3 (três) profissionais por categoria, devendo somar no mínimo 40 horas/semanais. O processo de trabalho, a combinação das jornadas de trabalho dos profissionais das equipes e os horários e dias de funcionamento devem ser organizados de modo que garantam amplamente acesso, o vínculo entre as pessoas e profissionais, a continuidade, coordenação e longitudinalidade do cuidado. (BRASIL, 2017, p. 14).

De acordo com Morosini e Fonseca (2017) essas dez horas mínimas de trabalho por semana do corpo técnico de cada equipe de saúde da família, principalmente os profissionais de nível superior, como é o caso dos médicos, são insuficientes para toda uma complexidade existente no trabalho demandado pela Atenção Básica, além de implicar na perda do vínculo entre comunidade e profissional de saúde. Batalha e Lavor (2017) consideram que essa carga horária é danosa, avaliando também que, na prática, poderá ocorrer uma rotatividade de profissionais, ou seja, muitos médicos, por exemplo, irão trabalhar só um dia por semana, ou parte dele.

Para a equipe entrevistada, esse elemento da carga-horária mínima poderá gerar também a rotatividade dos profissionais e acabar tornando uma equipe de Atenção Básica em uma espécie de serviço de demanda ambulatorial, uma vez que todo o vínculo com a comunidade irá ficar fragilizado; nesse sentido, tem-se o trecho do seguinte relato, ipsis litteris:

Afeta completamente a continuidade, vínculo do profissional com a comunidade porque no meu entendimento desde o começo uma das maiores estratégias de uma equipe de saúde da família é você ter o vínculo para tentar com essa continuidade do trabalho ir melhorando a saúde da população, se for realmente assim vai ficar vindo um médico, depois outro e outro, fica uma coisa meio solta né? Isso pode enfraquecer! (MARIA). 
No tocante às funções de competência dos Agentes Comunitários de Saúde, essa nova PNAB inseriu procedimentos técnicos, a exemplo da aferição de pressão arterial, da medição de glicemia, da aferição da temperatura axilar, da limpeza de curativos e da orientação na administração da medicação do paciente em situação de vulnerabilidade. Cabe salientar que essas funções serão executadas mediante caráter excepcional, com o adendo de serem assistidas por profissional de saúde de nível superior membro da equipe, após treinamento específico e fornecimento de equipamentos adequados (BRASIL, 2017).

Entretanto, Peres (2017) , ao coletar informações de profissionais da Atenção Básica sobre esse tema, obteve respostas que traduziram a avaliação negativa. De acordo com uma profissional entrevistada, essas ações irão induzir o Agente Comunitário de Saúde a trabalhar com funções do técnico em enfermagem, o que implica em transformar a natureza do trabalho desses profissionais. A percepção é que essa medida do governo visa transformar um trabalho humanizado em uma atividade meramente técnica. Para a equipe entrevistada, o discurso a respeito desse tema é semelhante ao encontrado por Peres (2017), uma vez que a realização de procedimentos dessa magnitude implica em uma qualificação e maior responsabilidade. A equipe questiona também se essas atividades irão de fato vir acompanhadas de capacitação e aumento salarial, pelo fato de introduzirem novas funções além das que já existem, como pode ser observado no trecho da exposição a seguir:

[...] eu pensei assim quando vi esse problema: E o técnico na unidade que é que ele vai fazer? E assim se a gente ficar chegando nas casas para aferir pressão, acontece um problema aí foi o agente de saúde, se acontecer algum problema, se morrer foi o agente de saúde que causou, só que a gente tem orientação, vai ter tudo, mas assim, eu mesmo não acho bom. Eu acho que a gente deve identificar o problema e falar, realizar esses procedimentos na casa eu não gostaria que fosse assim, vai acarretar muitos trabalhos para gente, basta o que a gente já tem! (NANA).

Por outro lado, o Ministério da Saúde argumenta que essas atividades irão valorizar a atuação dos Agentes Comunitários de Saúde e dos Agentes de Combate a Endemias por considerar que essa formatação é flexível às múltiplas realidades do território brasileiro. Apesar dessa posição, Peres (2017) destaca que o Ministro da saúde Ricardo Barros expôs em audiência pública no dia 10 de agosto de 2017, antes ainda da aprovação da PNAB, que deveria existir apenas um profissional que realizasse visitas domiciliares (unindo o Agente de Comunitário de Saúde e o Agente de Combate a Endemias em um único profissional) para o acompanhamento e elaboração de procedimentos técnicos frente aos usuários do serviço. 
Dessa forma, o que se percebe de modo geral é que para os defensores das reformulações da PNAB, há o elemento da gestão em um momento de austeridade fiscal promovida pela Emenda Constitucional número 95/2016. Para esses, a nova PNAB traz flexibilidade e resolubilidade de problemas no território nacional, como bem aponta o Ministro Ricardo Barros, em trecho citado por Batalha e Lavor (2017, p. 11), in verbis, “[...] a revisão na PNAB vai permitir que municípios se adequem às restrições orçamentárias, vamos passar a financiar o mundo real.”. Ainda, segundo esses autores, os críticos a essas reformulações endossam o argumento de que o mundo real apontado pelo Ministro, possui uma visão estritamente mercadológica, influenciada pela Emenda Constitucional n ${ }^{\circ} 95$, ao desenhar um cenário de menos investimentos por parte do Estado.

Para a equipe local entrevistada, essas mudanças não passam de uma forma de flexibilizar o trabalho da Atenção Básica à Saúde. Segundo interpretação dos profissionais, essas medidas não necessariamente irão trazer uma maior resolubilidade aos problemas de saúde da população; pelo contrário, o fato de haver um movimento que coloca em cheque a questão do vínculo com a comunidade, pode surtir um efeito contrário de afastamento da comunidade a esse serviço. Cabe destaque que um dos traços marcantes que representam a Estratégia Saúde da Família é justamente a criação de vínculo entre usuários do serviço e profissionais, de modo a tratar as demandas de saúde para além de uma perspectiva biomédica e mercadológica.

\section{Considerações finais}

A incontestável importância das ações promovidas pela Estratégia Saúde da Família para além de uma perspectiva biomédica, já traduz o ganho que a saúde pública brasileira obteve (MARTINS, 2017). Assim sendo, a perspectiva apresentada neste artigo implica a reflexão sobre o lugar estratégico da PNAB na saúde pública brasileira e qual a prioridade dessa saúde para o país.

O percurso metodológico adotado no estudo e os resultados obtidos demonstram a insegurança frente às reformulações da PNAB, que variam de um âmbito macro institucional representado pelo Conselho Nacional de Saúde, e, em um plano micro, por meio dos discursos da equipe de Saúde da Família entrevistada. Nesse sentido, cabe destacar que foi possível perceber inquietações, dúvidas, críticas e surpresas dos impactos que possivelmente essas reformulações irão surtir na Atenção Básica. É necessário levar em consideração que o Brasil vive um momento delicado relacionado à política e à economia e que muitas das ações políticas se manifestam para além da institucionalidade vigente, como demonstram os resultados deste estudo. Em um momento de extremos políticos e de medidas econômicas austeras, toda forma de flexibilização nas políticas públicas é justificada pela necessidade de enquadramento fiscal. Atenta-se também ao fato da própria argumentação do Ministro da Saúde que enfatiza a necessidade de mudanças para viabilizar o "financiamento do real". Contudo, para o recorte 
analítico adotado na pesquisa, o trabalho desenvolvido pelos profissionais entrevistados supera as expectativas da PNAB, uma vez que esses profissionais são peças chaves de um elo de confiança junto à comunidade. Nesse quadro, a perspectiva de financiar o "real" pode deixar de considerar esse importante aspecto da Atenção Básica e levar em consideração interesses que não coadunam com os princípios do SUS.

Salienta-se também que esse estudo abre espaços para investigações futuras, principalmente no que diz respeito ao processo participativo de decisões na saúde pública. Como exemplo, pode-se aprofundar estudos relacionados ao papel do Conselho Municipal de Saúde na condução de decisões geridas na esfera nacional, bem como sobre o papel comunicativo dessa instância para a perspectiva da democracia na saúde pública.

Elementos como a burocratização e a verticalização das decisões expressas nos resultados dessa pesquisa apontam a fragilidade e a acomodação da democracia brasileira aos ditames da acumulação capitalista. Também cabe o destaque quanto ao elemento político na condução das políticas públicas, com observância a noção de totalidade expressa no processo de crise política e econômica ao qual o Brasil vivencia. De modo geral, reafirma-se a importância do fortalecimento da Atenção Básica à Saúde e em especial da Estratégia Saúde da Família, como um meio de dar continuidade ao acesso à Saúde Pública e de qualidade. Em primeira instância o fortalecimento da PNAB passa necessariamente pela esfera de um projeto político que considere saúde como um investimento e não como despesa.

\section{Referências}

BATALHA, Elisa; LAVOR, Adriano. Atenção Básica não é atenção mínima. Escola Nacional de Saúde

Pública. Fundação Oswaldo Cruz. Radis. 2017, nº183. Disponível em: http://www6.ensp.fiocruz.br/radis/revista-radis/183. Acesso em: 22 jan, 2018.

BONI, Valdete; QUARESMA, Sílvia Jurema. Aprendendo a entrevistar: como fazer entrevistas em ciências sociais. Em Tese, Florianópolis, v. 2, n. 1, p. 68-80, jan. 2005. ISSN 1806-5023. Disponível em: https://goo.gl/VS8xjQ. Acesso em: 16 set. 2018.

BRASIL. Ministério da Saúde. Portaria no. 325/GM, de 21 de fevereiro de 2008. Estabelece prioridades, objetivos e metas do Pacto pela Vida para 2008, os indicadores de monitoramento e avaliação do Pacto pela Saúde e as orientações, prazos e diretrizes para a sua pactuação. Diário Oficial da União. 22 Fev 2008. 
BRASIL. Ministério da Saúde. Secretaria de Atenção à Saúde. Departamento de Atenção Básica. Política Nacional de Atenção Básica. Brasília : Ministério da Saúde, 2012.

BRASIL. Ministério da Saúde. Quais as mudanças na atualização da PNAB? 2017. Disponível em: http://dab.saude.gov.br/portaldab/noticias.php?conteudo=_\&cod=2433. Acesso em: 36 dez. 2017.

CAMPOS, Gastão Wagner de Sousa et al . Direito à saúde: o Sistema Único de Saúde (SUS) está em risco?. Interface (Botucatu), Botucatu , v. 20, n. 56, p. 261-266, Mar. 2016 . Disponível em: https://goo.gl/S1ciPg. Acesso em: 22 jan. 2018.

Escola Politécnica de Saúde Joaquim Venâncio (EPSJV) . Nota de posicionamento da EPSJV sobre o VII Fórum Nacional de Gestão da Atenção Básica. Escola Politécnica de Saúde Joaquim Venâncio [data desconhecida]. Disponível em: https://goo.gl/MehqZr. Acesso em: 22 jan. 2018.

GIL, Antônio Carlos. Como classificar as pesquisas? In. .Como elaborar projetos de pesquisa. $4^{a}$ ed. São Paulo: Atlas, 2002, p. $41-57$.

Antônio Carlos. Pesquisa Social. In: A. Métodos e técnicas de pesquisa social. 6. ed. São Paulo: Atlas, 2008, p. $26-32$.

Instituto Brasileiro de Geografia e Estatística (IBGE). IBGE Cidades: Alagoa Nova, 2017. Disponível em: https://cidades.ibge.gov.br/brasil/pb/alagoa-nova/panorama . Acesso: 22 jan. 2018.

LAVILLE, Christian; DIONNE. . Capítulo 8: das informações à conclusão. In: A construção do saber: manual de metodologia da pesquisa em ciências humanas. Belo Horizonte: Editora UFMQ, 1999. pp. $197-231$.

MARTINS, Helena. Política Nacional de Atenção Básica expressará realidades locais. Revista Conasems. n.70, p. 13 - 32, 2017. Disponível em: http://www.conasems.org.br/. Acesso em: 22 jan. 2018. 
MATHIAS, Maíra. Escola Politécnica de Saúde Joaquim Venâncio. A crise por trás da nova PNAB, 2017. Rio de Janeiro: Fiocruz; Disponível em: http://www.epsjv.fiocruz.br/noticias/reportagem/a-crisepor-tras-da-nova-pnab. Acesso em 14 jan, 2018.

MOROSINI, Márcia Valéria Guimarães Cardoso; FONSECA, Angélica Ferreira. Revisão da Política Nacional de Atenção Básica numa hora dessas?. Cad. Saúde Pública, Rio de Janeiro , v. 33, n. 1, e00206316, 2017. Disponível em: http://www.scielo.br/scielo.php?script=sci_arttext\&pid=S0102311X2017000100301\&lng=en\&nrm=iso. Acesso em: 22 jan. 2018.

PERES, Ana Cláudia. ACS em risco. Escola Nacional de Saúde Pública. Fundação Oswaldo Cruz. Radis, 2017, nº183, pp. 16 - 20. Disponível em: https://goo.gl/PM1sDT. Acesso em: 12 jan. 2018.

PRODANOV, Cleber Cristiano. Metodologia do trabalho científico : métodos e técnicas da pesquisa e do trabalho acadêmico. 2. ed. Novo Hamburgo: Feevale, 2013.

RADIS. Entrevista com Shirley Díaz Morales. Escola Nacional de Saúde Pública. Fundação Oswaldo Cruz. Radis comunicação e saúde. 2017 dez; 183:32-33.

SEVERINO, Antonio Joaquim. Metodologia do trabalho científico. 23. ed. São Paulo: Cortez, 2007.

SILVA, Claudio Valdivino ; LIMA SILVA, Diego Ferreira; SOUZA, Elza Maria de. A participação da sociedade civil na democratização do setor de saúde no Brasil. Rev. bras. educ. med., Rio de Janeiro, v. 37, n. 2, p. 254-259, Junho 2013 . Disponível em: https://goo.gl/5ktGLU. Acesso em: 22 jan. 2017.

Recebido em: julho de 2019. Aprovado em: setembro de 2019. 